\title{
ROL DE LA SOCIEDAD DE CIRUJANOS DE CHILE EN LA FORMACIÓN DE CIRUJANOS GENERALES
}

\author{
Residents surgical training. Role of the Society of Surgeons
}

El país necesita de especialistas tanto en Santiago como en regiones. Con la construcción de nuevos hospitales y la inversión en el sistema público, con mayores recursos para poder resolver patologías quirúrgicas en forma descentralizada, se hace imperioso contar con especialistas en los distintos centros. No obstante lo anterior, y asumiendo la necesidad cierta de contar con más profesionales, esto no debiera ir asociado a alejarse de los estándares de calidad en la formación de cirujanos recomendados internacionalmente y también por nuestra Sociedad.

- Dentro de los estándares de formación, destacan:

- Acreditación periódica de los centros formadores.

- Rotaciones en centros de alta y mediana complejidad.

- Unificar contenidos cognitivos (teóricos) como actividad transversal de los residentes.

- Entrega de competencias en el dominio actitudinal y valórico.

- Docencia sistemática en Servicios de Urgencia.

- Adecuada evaluación de desempeño.

Para lograr dichos estándares, es fundamental que los planes de formación de especialistas estén en manos de centros de experiencia y docentes calificados, es decir, centros universitarios.

En la actualidad existen al menos 16 universidades que ofrecen especialización en Cirugía General. Entre todas dan cuenta de un total aproximado de 100 cupos, es decir existirían alrededor de 300 Residentes en formación actualmente. Este número debiera ser suficiente para la contingencia de escasez de especialistas en Cirugía General.

La Corporación Nacional Autónoma de Certificación (CONACEM), ha tenido un papel preponderante en la certificación de especialistas desde su fundación en 1984. Gracias a sus características de representatividad, experiencia, mistica, transparencia, independencia y reconocimiento, esta corporación privada quedó designada, a través del Decreto Supremo $N^{\circ} 57$ del año 2008, junto a las universidades chilenas, como entidades capacitadas para certificar especialidades y subespecialidades médicas. Por lo tanto, CONACEM está centrada en la certificación de especialistas médicos y en la definición de especialidades médicas, no correspondiéndole la acreditación de los programas de formación de especialistas lo que es legalmente responsabilidad de las agencias acreditadoras.

Las vias a través de las cuales CONACEM certifica especialistas son 3: 1) Haber aprobado un programa universitario acreditado (APICE, ASOFAMECH); 2) Formación en el extranjero, previo análisis de homologación a la formación nacional y a someterse a examen teórico y práctico y 3) Por adiestramiento en práctica.

Es precisamente el punto 3 el que genera algunas inquietudes en los centros formadores universitarios y en nuestra Sociedad de Cirujanos. Entre el año 1985 y el 2012, cerca de un cuarto (23\%) de los especialistas de Cirugía General, lo hicieron a través de esta vía. El realizar un adiestramiento en práctica, pudiera tener ciertos beneficios y falencias respecto a las formaciones universitarias. Beneficios en el hecho que son profesionales médicos que al mismo tiempo de estar formándose, reciben remuneración habitualmente superior a la de cualquier Residencia. Tiene posibilidad de generar ingresos extras por turnos de urgencia (28 horas) y ayudantías quirúrgicas como parte de su adiestramiento. Las exigencias horarias suelen ser menores también, al no tener rotaciones estructuradas y monitoreadas por docentes calificados (profesores universitarios). Dentro de las falencias, se pueden nombrar la ausencia de cursos estructurados teóricos y/o actividades complementarias como cursos de medicina basada en evidencia, aspectos legales del ejercicio 
de la profesión, metodologías de investigación, administración en salud y entrenamiento en laboratorios de simulación entre otras. Además de la ausencia de las respectivas evaluaciones por rotación a cargo de especialistas en cada área.

Dado el merecido prestigio y reconocimiento de CONACEM, no es posible en las condiciones actuales, impedir que esta corporación certifique especialistas con adiestramiento en práctica, a pesar del considerable aumento de formaciones universitarias tanto en Santiago como en Regiones. Sin embargo, sí es responsabilidad de nuestra Sociedad, exigir que los candidatos a certificación por la vía del adiestramiento, cumplan con las mismas exigencias que poseen las formaciones universitarias de manera de no incentivar estas formaciones en paralelo a las universidades y en caso de que existan, sean de un nivel similar ratificado por una comisión, antes de permitir que den examen teórico y práctico.

La Sociedad de Cirujanos de Chile debiera preocuparse de velar por el cumplimiento de los estándares de la formación del cirujano y a su vez incrementar el número de especialistas aumentando los cupos de los centros universitarios reconocidos y en lo posible debidamente acreditados. Es una tarea pendiente revisar las exigencias para certificación en las que se basa actualmente CONACEM y nivelarlas con la de centros formadores universitarios de manera de optimizar la calidad de nuestros futuros especialistas.

\section{Referencias}

1. Hepp J, Csendes A, Ibáñez F, Llanos O, San Martín S. Programa de la especialidad Cirugía General. Definiciones y propuestas de la Sociedad de Cirujanos de Chile. Rev Chil Cir. 2008;60:79-85.

2. Bustamante M, Espinoza R, Hepp J, Martínez J. Estándares de la formación del cirujano. Visión de la Sociedad de Cirujanos de Chile. Rev Chil Cir. 2015;67:102-8.

3. López J. Certificación y recertificación de especialistas en Cirugía General. Una mirada desde CONACEM. Rev Chil Cir. 2013;65:560-6.

4. Bustamante M. Desafíos en la formación del cirujano. Editorial. Rev Chil Cir. 2015;67:348-9.

5. CONACEM. Reglamentos Generales. Requisitos Específicos. 2015.

Dr. Nicolás Jarufe C.

Profesor Asociado

Jefe Departamento de Cirugía Digestiva Pontificia Universidad Católica de Chile Director Sociedad de Cirujanos de Chile

Dr. Jorge Martínez $C$. Profesor Asociado Jefe Programa de Cirugía General Pontificia Universidad Católica de Chile Presidente Departamento de Educación Sociedad de Cirujanos de Chile 